\title{
Começar com começar: leituras sobre as configurações de começar em português europeu contemporâneo
}

\author{
Helena Alzamora \& Clara Nunes Correia \\ Universidade NOVA de Lisboa, CLUNL
}

\begin{abstract}
:
The main objective of this work is the analysis and description of the values of começar in european Portuguese, in order to explain the differences that can be observed in the various configurations in which it occurs, such as < x começar y >, < começar ADV >, < começar Prep INF>, < começar Prep SN>. We try to identify the principles that generate invariance, in spite of the multiple functions these configurations may be associated with. By doing this, we intend to explain the semantic and enunciative properties of this verb in order to describe and explain its different functions. Therefore, it is suggested that the grammatical constructions containing começar can be addressed using a theoretical-methodological support designated by "Schematic Form". On this hypothesis, see among others Culioli (1990), Paillard (2000), Correia \& Coutinho (2006). The "Schematic Form" represents an invariant structure and, at the same time, it shows the deformability originated by the relationship between the verb and its arguments, or among the arguments themselves. We believe that this hypothesis allows for a better understanding of the functioning of the sequences in which this verb occurs.
\end{abstract}

Keywords: começar (to start /to begin), verbal typologies, predicative relation, notional domain, Schematic Form

Palavras-chave: v. começar, tipologias verbais, relação predicativa, domínio nocional, Forma Esquemática

\section{Introdução}

O estudo das configurações verbais numa dada língua pode incidir sobre aspetos diferenciados que se centram quer em perspetivas classificatórias, quer em perspetivas que incidem sobre os valores que as formas que integram essas configurações desencadeiam. Assim, à pluralidade de classificações que podem estar associadas a um dado verbo (pleno, leve, (semi)auxiliar, ...), por exemplo, acrescem categorizações de natureza sintático-semântica, destacando-se, neste caso, as suas propriedades temporais, aspetuais e/ou modais (Binnick, 1991).

Este trabalho, tendo por base a análise das propriedades de começar em português europeu contemporâneo (PE), tem como objetivo central mostrar de que forma essas propriedades convergem para a interpretação dos seus valores. Assumindo-se que começar pode ser analisado como verbo delimitador de fronteira (tal como acabar ou terminar, ...), verificamos que a sua análise enquanto verbo pleno possivelmente a configuração mais estável que lhe está associada - assenta na relação predicativa (ou proposição) < x começar $\mathrm{y}\rangle$, em que x e y são lexicalizados enquanto argumentos nominais. Já quando ocorre como (semi)auxiliar, começar integra configurações, tradicionalmente definidas como construções perifrásticas, representadas esquematicamente por < começar Prep INF >. Sob o ponto de vista aspetual, por sua vez, observa-se que as propriedades de começar apontam para a construção de valores de atelicidade (* comecei | ? começo |? vou começar o trabalho em duas horas), sendo, no entanto, e de acordo com Verroens (2014), neutro em relação às propriedades de perfetividade que pode exibir.

Assim, e tendo em conta as diferentes configurações em que começar ocorre, propomos mostrar de que forma as construções que resultam dessas configurações podem ser aproximadas e estabilizadas. Esta proposta de análise tem subjacente a assunção de que, ao ativar a construção, delimitação e estruturação 
/fracionamento do um domínio nocional da noção que lhe é subjacente, e dos diferentes ajustamentos topológicos das suas diferentes ocorrências, este verbo permite exibir um conjunto de propriedades invariantes.

A análise que nos propomos realizar assenta nos pressupostos desenvolvidos na perspetiva da Teoria Formal Enunciativa (TFE), a partir das propostas de, e.o., Culioli (1990) e (1995), dando-se especial relevo à validação da sua Forma Esquemática $(\mathrm{FE})^{1}$, enquanto estrutura invariante, mas, simultaneamente, suscetível de integrar deformações originadas nas relações entre começar e os seus argumentos e entre os argumentos entre si.

\section{Começar: propriedades topológicas e a definição da Forma Esquemática}

A partir das contribuições dadas pelos trabalhos desenvolvidos na TFE, sob o ponto de vista topológico², começar marca a fronteira de abertura de um domínio nocional, definido como o espaço das ocorrências de uma noção.

Defende-se, assim, que uma das características essenciais de começar é implicar uma primeira construção de uma noção (P), por intermédio de uma antecipação. Começar $\mathrm{P}$ põe fim a ainda não $\mathrm{P}$ e implica que se espera a atualização de P. Esta hipótese pode ser verificada nos exemplos que serão analisados ao longo deste trabalho.

Em termos gerais, tal como se representa no diagrama abaixo ${ }^{3}$ (figura 1) e seguindo Culioli (1995), considera-se que uma das características inerentes à estruturação o domínio nocional passa necessariamente pela orientação das zonas topológicas que o integram $(\mathrm{E} \rightarrow \mathrm{I} / \mathrm{I} \rightarrow \mathrm{E})$ :

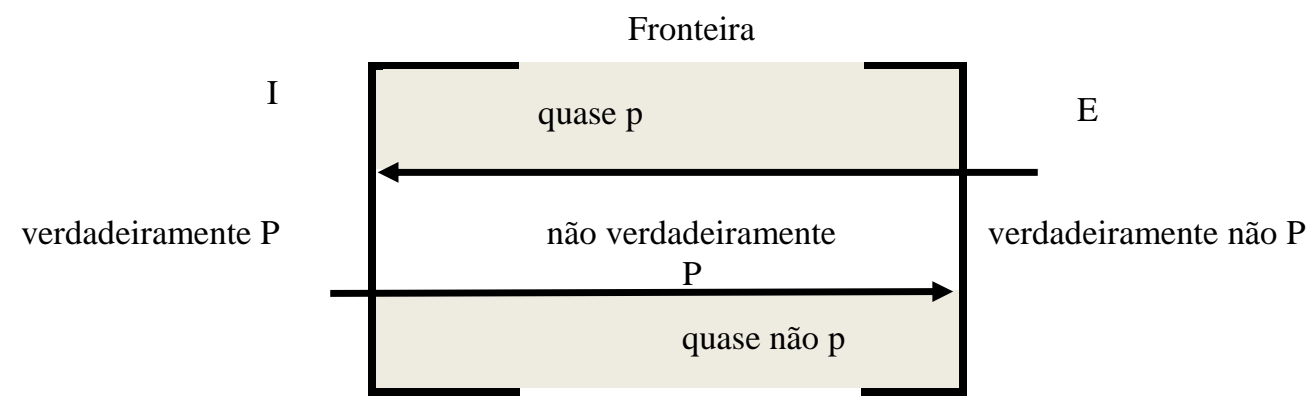

Figura 1

Como se pode observar, o domínio de validação da noção compreende a zona I (constituída pelas ocorrências positivas) e a zona E (constituída pelas ocorrências negativas). As zonas I e E são complementares e contêm todas as ocorrências possíveis de uma noção. Por esta razão, as ocorrências de uma noção, ou são situadas pelo enunciador na zona I ou na zona E, ou são construídas como validáveis, situandose, neste caso, na zona IE (Interior/Exterior). Neste caso, a representação topológica é uma bifurcação que dá acesso a I ou a E (Figura 2):

\footnotetext{
${ }^{1} \mathrm{O}$ conceito de Forma Esquemática foi definido inicialmente por Culioli (1990), tendo sido posteriormente reformulado por Paillard (2000). Sobre a operacionalidade deste conceito na descrição de verbos do português, v., e.o., Correia \& Coutinho (2006) e Correia (2010).

${ }^{2}$ Sobre as propriedades topológicas de commencer (para o francês), cf., sobretudo, Franckel (1989) e Camus (2004); para começar (em português) v., sobretudo, Alzamora (2018) e Alzamora \& Correia (2018).

${ }^{3}$ A partir de, e.o., Culioli (1997) e Moreira (2005).
} 


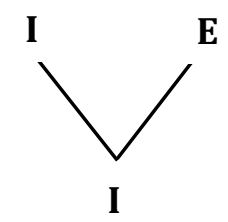

Figura 2

A partir desta análise pode, então, defender-se que as propriedades semânticas associadas a começar, assentes nas suas propriedades topológicas, são responsáveis por uma das suas características distintivas: começar delimita e estrutura a zona de fronteira de abertura do domínio nocional. Em termos gerais, a fronteira de abertura, marcada por começar, mobiliza uma localização espacial (começar num dado lugar) ou temporal (começar num dado momento), construindo, simultaneamente, como validável o domínio perspetivado como um todo.

De uma forma geral, assumimos, por isso, que são as suas características topológicas que nos permitem discutir, de forma sustentada, quer a aparente diversidade de configurações em que ocorre, quer os valores que evidencia.

\section{Começar: configurações e valores}

Tendo em conta as possíveis configurações em que começar ocorre e assente na observação dos dados que apresentámos acima, podemos caracterizar começar a partir de três características fundamentais: as entidades construídas por começar têm dimensões delimitadas por fronteiras; começar desencadeia e delimita, numa dimensão temporal, espacial ou nocional, uma sequência de unidades ordenadas; a sequência de unidades ordenadas implica a existência de uma deslocação realizada pelo argumento externo do verbo começar.

Tendo em atenção as diferentes ocorrências de começar, percorreremos, de seguida, algumas das configurações em que começar ocorre, relacionando essas configurações com os valores semânticos que as individualizam, por um lado, e que as relacionam, por outro. Esta análise permitirá encontrar padrões de aproximação entre diferentes configurações.

\section{1. < começar Prep INF >}

Esta construção pode ser encontrada em configurações em que < começar $a$ INF > está habitualmente associada à construção da fase inicial de um processo ${ }^{4}$, como nos exemplos

(1) O Pedro começou a ler (com 5 anos | o livro que lhe dei | jornais, quando tinha 15 anos).

(2) Começou a chover (neste momento | durante a noite).

(3) Começou a chover (mais) em setembro.

\footnotetext{
${ }^{4}$ Para a análise da configuração < começar a INF >, ver, numa perspetiva diferente, e.o., Cunha (1998), Oliveira (2003) e Oliveira, Cunha \& Gonçalves (2004). Note-se que, de acordo com Oliveira, Cunha \& Gonçalves (2004: 144), começar, nestas construções, define um estado preliminar, responsável pelas características sintático-semânticas que evidencia: «(...) We hypothesise that the 'input' for this verb is identified with a period leading up to, but not including, the initial portion of a basic or derived process. (...)»
} 
Nestes três exemplos, a construção < começar $a$ INF > marca o início de uma situação não delimitada à direita. Na ausência de outros marcadores temporais, a situação construída é localizada, através do pretérito perfeito simples, em relação $\mathrm{T}_{0}$, como anterior ao tempo de referência e podendo estar em curso em $\mathrm{T}_{0}$. Como se verifica no exemplo (2), os adverbiais neste momento e durante a noite desencadeiam leituras temporais distintas. $\mathrm{O}$ adverbial neste momento permite ancorar a relação predicativa ao tempo da enunciação. $\mathrm{O}$ pretérito perfeito situa $\mathrm{T}_{2}$ num tempo anterior e contíguo a $\mathrm{T}_{0}$.

As propriedades de começar (delimitação e fracionamento de um domínio nocional) e a característica de poder desencadear sequências de unidades ordenadas, tal como se referiu anteriormente, justificam também que, regra geral, não sejam possíveis sequências em que começar coocorre com predicadores classificados, na tipologia de Vendler (1967) como eventos instantâneos, por exemplo, sair, cair, morrer. Esta impossibilidade verifica-se, sobretudo, pelo facto de estes predicadores definirem uma situação que é representada por um intervalo fechado, sem dimensão. A noção de sequência e de não dimensão do intervalo da situação excluemse mutuamente. No entanto, deve notar-se que, tal como exemplificado em (3), em certas situações definidas a partir de eventos instantâneos pode existir a coocorrência com começar. Isto acontece, quando determinados contextos permitem marcar o valor aspetual de iteratividade. O valor do predicador não é anulado, ajustandose, no entanto, o valor de iteratividade à propriedade de sequência ${ }^{5}$ :

(4) O Pedro começou a chegar tarde às aulas (todos os dias).

A terceira característica do verbo começar obriga a que o argumento externo esteja implicado numa deslocação, deslocação essa que pode assumir uma dimensão espacial, temporal ou espácio-nocional. Topologicamente dá-se uma deslocação no interior do domínio nocional, na zona do gradiente, visando o centro organizador e centro atractor da noção. Estas características podem ser encontradas nos exemplos que se apresentam seguidamente:

(1) O Pedro começou a ler (com 5 anos $\mid$ o livro que lhe dei | jornais, quando tinha 15 anos).

(1') $\mathrm{O}$ atleta começou a correr a maratona.

Nas sequências < $\mathrm{x}$ começar Prep INF> e nas sequências < $\mathrm{x}$ começar $\mathrm{SN}>$ com um $\mathrm{SN}$ deverbal derivado de predicadores caracterizados, aspetualmente, Atividades ou Eventos (cf. (5)), a deslocação pela sequência das unidades ordenadas remete para a dimensão temporal de uma situação (a primeira etapa de uma deslocação temporal, intrinsecamente dinâmica e orientada) ${ }^{6}$. Quando coocorre com um argumento interno expresso por um SN não deverbal (cf. (5')), a ideia de deslocação implica que o sujeito efetua um trajeto abstrato na dimensão espacio-nocional inerente a esse objeto:

(5) O Pedro começou a leitura do livro que lhe deste.

(5') O Pedro começou o livro (a ler $\mid$ a escrever um livro).

\footnotetext{
${ }^{5}$ Refira-se, contudo, que sequências construídas com começar tendo por argumento interno nominalizações deverbais derivadas de eventos instantâneos são totalmente agramaticais:

(a) * O Pedro começou a chegada. |* O Pedro começou a chegada às aulas. |*O Pedro começou a chegada tarde todos os dias.

${ }^{6}$ Os valores marcados por estas construções não são indissociáveis de todas as interações que se estabelecem nas configurações em que se inscrevem, nomeadamente, da determinação dos argumentos (cf. Pereira 2009):

(b) O Pedro começou a correr. (antes não corria) $\mid$ O Pedro começou a correr há meia hora.

(c) O Pedro começou o trabalho | alguns trabalhos $\mid *$ trabalhos.

(d) $O$ Pedro começou a ler. (antes não sabia ler)) $\mid$ O Pedro começou a ler o jornal / jornais.

(e) * O atleta começou a chegar. | Os atletas começaram a chegar.
} 
A observação dos dados permite, assim, e na sequência de trabalhos já realizados ${ }^{7}$, reforçar a defesa de que as propriedades de começar, ao definirem a marcação de uma fronteira de abertura, representável por um intervalo sem dimensão, impedem a sua coocorrência com predicadores caracterizados pela ausência de fronteiras.

A ideia de uma deslocação implica e justifica, ainda, as restrições de coocorrência de começar com predicadores estativos. Só os estados faseáveis ${ }^{8}$ podem coocorrer com começar, não havendo, geralmente, qualquer coocorrência com estados denotadores de uma propriedade permanente ${ }^{9}$. No entanto, as construções < x começar SN > são, regra geral, incompatíveis com um argumento interno que denote qualquer tipo de Estado:

(6) * O Pedro começou a ser alto.

(6’) O Pedro começou a ser simpático comigo.

$(6 ”)$ * O Pedro começou a sua altura / a sua simpatia.

As propriedades de começar e as características explicitadas anteriormente permitem, por outro lado, a descrição da construção < começar por INF > e a explicação do seu funcionamento e dos valores por ela marcados.

Esta construção tem, em certa medida, propriedades idênticas a < começar $a$ INF >. No entanto, enquanto < começar $a$ INF > remete para a construção de uma situação singular, isto é, para o começo de um único acontecimento (no sentido lato do termo: Evento ou Estado faseável), a construção < começar por INF $>$ remete para a construção de uma série de situações de natureza distinta, indiciando, muitas vezes, uma leitura iterativa. Assim, esta perífrase verbal desencadeia a construção de uma série de acontecimentos, ou seja, remete para o primeiro acontecimento de uma série, a que se seguirá, necessariamente, um novo acontecimento da série.

$\mathrm{Se}<$ começar a INF > implica, como foi referido anteriormente, a construção da fronteira de abertura de um domínio nocional e, simultaneamente, a construção do domínio $(\mathrm{P})$, por intermédio de uma antecipação, < começar por INF > implica a construção de uma série de diferentes domínios nocionais $\left[\mathrm{P}_{1}+\mathrm{P}_{2}+\mathrm{P}_{3}+\ldots\right]$, por intermédio de uma antecipação. < Começar por INF > marca a fronteira de abertura da série $\left(\mathrm{P}_{1}\right)$, pondo fim a ainda não $\left[\mathrm{P}_{1}+\mathrm{P}_{2}+\mathrm{P}_{3}+\ldots\right]$. Assim, esta construção marca o início de uma série de situações, situações essas que, à exceção da primeira da série, podem estar, ou não, marcadas textualmente:

(7) Numa prova de Triatlo, os atletas cumprem individualmente um percurso onde começam por nadar, habitualmente em águas abertas (mar, lagos ou rios), depois andam de bicicleta, em estrada ou todo-oterreno (BTT) e acabam a correr.

[http://www.federacao-triatlo.pt/trijamor/triatlo.html]

(8) O Pedro começou por dizer que não participava no projeto.

Os valores marcados por esta construção decorrem, por sua vez, das propriedades da preposição por, que concorrem, também, para a construção das ocorrências plurais. Esta hipótese assenta na proposta de Hamma (2006: 12) que define as propriedades da preposição par, para o francês. De acordo com a autora, esta preposição seleciona um elemento particular de um conjunto de elementos potenciais: « (...) même dans les périphrases verbales en $\operatorname{par}(\ldots)$ où l'énoncé implique une succession de procès, avec un certain ordre $(\ldots){ }^{10}$.

7 Ver, e.o., Cunha (1998) e Oliveira, Cunha \& Gonçalves (2004), para o português, Franckel (1989), para o francês e Squartini (1998), para as línguas românicas.

${ }^{8}$ Sobre a caracterização, em português, dos Estados (faseáveis / não faseáveis), ver, e.o., Cunha (2004).

${ }^{9}$ Note-se que, com predicadores estativos desta natureza poderão se construídas algumas sequências perfeitamente gramaticais: $O$ Paulo começou a ser alto, quando tinha quinze anos Ainda assim, esta compatibilidade é muito restrita (cf. * $O$ João começou a ser baixo, quando tinha quinze anos. |* O prédio começou a ser alto, quando lhe acrescentaram três andares.).

${ }^{10}$ Sobre o valor semântico das preposições, trabalhadas no quadro da TFE, ver, e.o., Paillard (2002), Franckel \& Paillard (2007) e Costa (2014). Para um estudo mais generalista das preposições, ver, e.o., Cadiot (1997). 
2.2. A construção da dimensão espacial, temporal, ou espacio-nocional de configurações com começar.

Nos exemplos (9) e (10), que se apresentam seguidamente, com SPs marcadores de lugar e de tempo cujo núcleo é a preposição em, começar marca a fronteira de abertura dos domínios nocionais expressos por $\mathrm{C}_{0}$ (a Corrida do Tejo / as Festas do Mar) e os SP (em Algés / no dia 17 de agosto) permitem marcar deslocações de ordem espacial (começa num lugar e desenvolve-se ao longo de um percurso espacial) ou de ordem temporal (começa num dado tempo e percorre um período temporal):

(9) A Corrida do Tejo começa em Algés e acaba em Oeiras.

(10) As Festas do Mar começam no dia 17 de agosto.

Quando existe coocorrência de começar com a preposição com e se a configuração integra um SN não deverbal, como em (11) e (12), a ideia de deslocação implica que o sujeito efetue um trajeto de ordem temporal:

(11) O Pedro começou com um texto / textos muito simples e agora escreve muito bem.

(11') * O Pedro começou texto.

(12) O Pedro começou com parvoíces.

(12') * O Pedro começou com (uma) parvoíce.

Uma leitura possível dos exemplos (11) e (12) parece permitir encontrar uma proximidade de funcionamento entre começar com SN e as construções < começar por INF > ou < começar $a$ INF >, dependendo da formatação do SN que instancia o argumento interno [ \pm ] discreto). Assim, se há uma formatação discreta do $\mathrm{SN}^{11}$ (um texto / textos / * texto), como no caso de (11), parece existir uma aproximação de valores de começar com e < começar por INF >; se a proximidade de interpretação é feita com < começar a INF >, como acontece em (12), o N apresenta uma natureza [-] discreta: parvoíces / * (uma) parvoíce ${ }^{12}$.

Em ambos os casos, começar desencadeia, implicitamente, ocorrências nominais e a construção do valor de iteratividade. Deste modo, em (11) e em (12), cabe ao SN desencadear e delimitar uma sequência de unidades ordenadas, marcando uma deslocação e definindo um percurso sobre essas unidades. Começar com um texto, no exemplo (11), implica que, na sequência desse, foram escritos outros textos, sequencialmente.

Esta descrição permite, igualmente, explicar o funcionamento desta configuração num exemplo como o que se apresenta em (13):

(13) O filme começa com uma cena fantástica.

Neste caso, em que não há uma correspondência direta com < começar Prep ( a / por) INF >, é ativado um valor associado a uma operação marcadora da sucessividade das ocorrências da noção /cena/.

Esta sucessividade de unidades (as cenas do filme) desencadeia, assim, uma operação de percurso. Neste caso, a sucessividade definida é de ordem espácio-nocional. Assumindo-se que um filme é constituído por diferentes cenas, começar constrói a fronteira de abertura do domínio nocional associado ao argumento

\footnotetext{
${ }^{11} \mathrm{O}$ conceito de 'formatação discreta' assenta nas propostas desenvolvidas no quadro da TFE, tendo em conta que qualquer ocorrência nominal é formatada topologicamente em relação a um padrão tipo num dado domínio nocional. É esta propriedade que permite que estas ocorrências possam ser enumeradas diretamente.

${ }^{12}$ A ocorrência de um N discreto nestas configurações apenas é possível em situações em que é construído um valor tipo ou valor de alto grau. Sobre esta questão, ver, e.o., Correia (2002).
} 
externo (o filme) e a configuração, no seu todo, marca uma zona do interior do domínio, à direita e contígua à fronteira, bem como implica uma deslocação abstrata sobre a entidade filme.

Já o exemplo (14)

(14) De estagiário a chefe: conheça histórias de quem começou por baixo e hoje ocupa um cargo de liderança.

apresenta uma particularidade que o distingue dos restantes exemplos analisados até agora: começar, neste caso, não delimita o domínio associado ao argumento externo da relação predicativa, mas sim um argumento interno implícito, que não está marcado textualmente (por exemplo, uma carreira). De forma geral, pode assumir-se que, em interação com a preposição por, começar delimita uma sequência de unidades ordenadas e desencadeia uma deslocação que tem como ponto de partida a zona de fronteira (começar por baixo) e culmina na última unidade (ocupar um cargo de liderança), tal como ocorre textualmente no exemplo.

A coocorrência de começar com SPs pode, no entanto, verificar-se em configurações distintas das analisadas anteriormente. Veja-se, por exemplo, o caso de < x começar Prep SN $>$.

A análise e descrição de < x começar Prep SN >, quando o núcleo desse SP é a preposição de, como se verifica em

(15) O Pedro começou do nada $\mid$ do zero $\mid$ de baixo (e chegou onde chegou).

(16) Numa massagem, os movimentos rotatórios começam de baixo para cima.

permite verificar que as propriedades topológicas de começar, tal como se descreveu anteriormente, constroem a fronteira de abertura do domínio nocional. Contudo, neste caso, é desencadeada uma deslocação temporal sobre uma sequência de unidades caracterizadas, quer por uma sequência quantificada 'do nada para mais do que nada / do zero para mais do que zero', quer por uma orientação espacial, textualmente representada pela sequência começar de baixo para cima. Em qualquer dos casos a ideia de 'deslocação' (mesmo entendida de forma abstrata) é reforçada pelas propriedades da preposição de, responsável por ser marcadora, entre outros, dos valores de direccionalidade, o que não acontece com a preposição por.

\section{Algumas notas conclusivas}

Pelos dados observados e exemplificados ao longo deste trabalho, e seguindo a perspetiva de análise em que nos baseámos, começar ativa a construção, delimitação e estruturação/fracionamento do domínio, localizando, simultaneamente, uma dada relação predicativa numa zona interior (I) do domínio (coincidente com a fronteira (F) de abertura ou contíguo a F (à direita de F). Começar desencadeia, assim, a marcação da fronteira de abertura do domínio de uma noção, noção essa construída, quer pelo argumento externo $\left(\mathrm{C}_{0}\right)$, quer pelo argumento interno $\left(\mathrm{C}_{1}\right)$.

Estas propriedades podem ser esquematizadas e representadas pelo diagrama que se apresenta abaixo (Figura 3) e que, por sua vez, permite definir a Forma Esquemática deste verbo: 


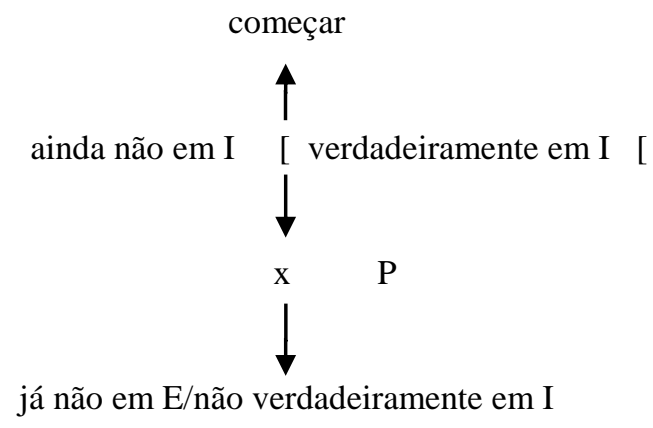

Figura 3

Em termos muito gerais, poder-se-á defender que sendo uma das características de começar implicar uma primeira construção de uma noção (P), através de uma antecipação (cf. Franckel, 1989), como se mostra na figura 3, em construções como começar $P$, o verbo põe fim a ainda não $P$ e implica que se espera a atualização de $\mathrm{P}$.

É por esta razão que começar fraciona o domínio da noção $\mathrm{P}$, definindo a sua delimitação, i.e., a construção da fronteira de abertura $(\mathrm{x}$ ) delimita a noção e perspetiva, como validável, o interior do domínio e a respetiva fronteira de fechamento. Por outras palavras, começar desencadeia a delimitação/fracionamento de uma parte do todo, mas também a construção do domínio como validável ${ }^{13}$.

Por outro lado, a plasticidade destas construções pode ainda ser analisada tendo em conta a deformabilidade de começar, quando associado a diferentes SPs Está associada a essa deformabilidade a variação que permite gerar princípios de invariância, a que se dá o nome de Forma Esquemática (FE). É a partir da FE que se constituem formas suplementares, que, em última análise são deformações da forma de base (Culioli, 1990: 115-116 adapt.).

Assim, e no seguimento de, e.o., Costa (2014), podemos assumir que a análise das preposições permite articular diferentes conceitos associados a propriedades topológicas (fronteiras, direccionalidade,...). Neste sentido, a deformabilidade das construções analisadas decorre das propriedades de começar e dos efeitos produzidos pelas preposições nas construções em que se inscrevem, tendo em conta a delimitação temporal, espacial, ou espacio-nocional, bem como a construção de fronteiras e de trajetórias.

A análise aqui apresentada, ancorada teórica e metodologicamente, poderá contribuir, como um todo, para a construção de hipóteses que permitam a generalização das propriedades de começar. Visando uma estabilidade descritiva do seu funcionamento, que ultrapasse uma estrita etiquetagem categorial, a análise e descrição que aqui se propõe poderá ser estabilizadora da diversidade de ocorrências de começar disponíveis em PE. Por sua vez, a definição da FE de começar permitirá, ainda, uma análise que pode ser generalizável a formas e construções que lhe sejam nocional e estruturalmente próximas.

\footnotetext{
${ }^{13}$ A esta propriedade, que se verifica com o verbo commencer, em francês, Camus (2004: 86-87) chama «o paradoxo da existência parcial».
} 


\section{Referências}

Alzamora, Helena Isabel (2018) As Perífrases Verbais no Português Europeu Contemporâneo. Tese de Doutoramento em Linguística. Universidade Nova de Lisboa (http://hdl.handle.net/10362/35961).

Alzamora, Helena Isabel \& Clara Nunes Correia (2018) Para lá das perífrases: os verbos começar e acabar enquanto verbos não auxiliares - algumas perspetivas. Cadernos WGT (Workshops em Gramática e Texto): (Novos) Balanços e Perspetivas. Abril 2018. Lisboa: CLUNL - Grupo Gramática \& Texto. pp. 3942.

Binnick, Robert (1991) Time and the Verb. A Guide to Tense and Aspect. Oxford: Oxford University Press.

Cadiot, Pierre (1997) Les prépositions abstraites en français. Paris: Armand Colin.

Camus, Rémi (2004) Quelques aspects de commencer. LINX - Variation sémantique et syntaxique des unités lexicales: étude de six verbes français. 50|2004, pp. 81-101.

Correia, Clara Nunes (2002) Estudos de Determinação. A Operação de Quantificação-Qualificação em Sintagmas Nominais. Lisboa: FCG-FCT.

Correia, Clara Nunes (2010) Sobre os valores de ficar em Português Europeu. Estudos Linguísticos / Linguistic Studies. №5. julho 2010, pp. 153-161.

Correia, Clara Nunes \& Maria Antónia Coutinho (2006) Formes schématiques et schémas textuels. Revue de Sémantique et Pragmatique. Numéro 19-20, pp. 249-260.

Costa, Manuel Luís (2014) Os valores semânticos das preposições a, até e para em Português Europeu Trajetórias, fronteiras, telicidade e topologia. Tese de Doutoramento em Linguística. Universidade Nova de Lisboa (http://hdl.handle.net/10362/13088).

Culioli, Antoine (1990) Pour une Linguistique de l'Énonciation, Opérations et Représentations. Tome 1. Paris: Ophrys.

Culioli, Antoine (1995) Cogntion and representation in linguistic theory. Amsterdam/Philadelphia: John Benjamins.

Culioli, Antoine (1997) À propos de la notion. In Claude Rivière \& Marie-Line Groussier (eds.). La Notion. Paris: Ophrys, pp. 9-24.

Cunha, Luís Filipe (1998) Os operadores aspetuais do Português: contribuição para uma nova abordagem. Cadernos de Linguística, n. ${ }^{\circ} 1$. Porto: CLUP.

Cunha, Luís Filipe (2004) Semântica das predicações estativas para uma caracterização aspectual dos estados. Tese de Doutoramento em Linguística. Universidade do Porto.

Franckel, Jean-Jacques (1989) Étude de Quelques Marqueurs Aspectuels du Français. Genève/Paris: Librairie Droz.

Franckel, Jean-Jacques \& Denis Paillard (2007) Grammaire des Prépositions. Tome 1. Paris: Ophrys.

Hamma, Badreddine (2006) 7. Etat des lieux sur la sémantique de la préposition par. Modèles linguistiques 54 2006. La préposition en français (II), pp. 81-95.

Moreira, Benjamim (2005) Estudo de alguns marcadores enunciativos do português. Tese de Doutoramento em Linguística. Universidade de Santiago de Compostela.

Oliveira, Fátima (2003) Tempo e Aspecto. In Maria Helena Mira Mateus et al. (orgs.). Gramática da Língua Portuguesa. Lisboa: Editorial Caminho, pp. 127-178.

Oliveira, Fátima, Luís Filipe Cunha \& Anabela Gonçalves (2004) Aspectual Verbs in European and Brazilian Portuguese. Journal of Portuguese Linguistics, 3 (1), pp. 141-173.

Paillard, Denis (2000) À propos des verbes "polysémiques": identité sémantique et principes de variation. Syntaxe \& Sémantique - Sémantique du lexique verbal. N² 2. 2001/1. Caen: PUC, pp. 99-120.

Paillard, Denis (2002) Prépositions et rection verbale». Travaux de Linguistique 44, pp. 51-67.

Pereira, Susana (2009) A Semântica do Objecto: Aspecto e Determinação Nominal. Lisboa: FCG-FCT. 
Squartini, Mario (1998) Verbal Periphrases in Romance: Aspect, Actionality, and Grammaticalization. Berlin/New York: Mouton de Gruyter.

Vendler, Zeno (1967) Verbs and times». Linguistics in Philosophy. Nova Iorque: Cornell University Press, pp. 97-121.

Verroens, Filip (2014) La construction inchoative se mettre à: syntaxe, sémantique et grammaticalisation. L'Information Grammaticale 143, pp. 58-60. 